\title{
Factores predictivos de la eficacia del tratamiento con interferón de la hepatitis crónica C
}

Rodríguez Agulló JL. Factores predictivos de la eficacia del tratamiento con interferón de la hepatitis crónica C. An Med Interna (Madrid) 2001; $18: 349-350$.

El tratamiento de la hepatitis crónica $\mathrm{C}$ ha estado dominado por el uso del interferón desde el estudio piloto realizado por Hoofnagle y cols. (1) en 1986 cuando todavía se la llamaba hepatitis no-A no-B. Después de varios ensayos clínicos limitados, es en 1989 cuando se publican los ensayos aleatorizados de Davis (2) y DiBisceglie (3), este último doble ciego con placebo. La justificación del uso de interferón alfa se basaba en el efecto beneficioso del interferón bajando las transaminasas y mejorando la lesión hepática (3) o porque el interferón había demostrado su capacidad de inhibir la replicación de otros virus de la hepatitis (2).

En estos dos ensayos clínicos se uso una dosis de 1 a 3 MUI de interferón alfa tres veces por semana durante 24 semanas (2) o 1 MUI al día durante una semana y 2 MUI tres veces por semana durante las 23 semanas siguientes. Las razones para este protocolo de tratamiento no se explicaron bien ("para evitar los efectos indeseables") y quizás eran copia de otros protocolos de tratamiento. Los resultados de estos protocolos de tratamiento eran modestos pero evidentemente eran mucho mejores que los que se conseguían anteriormente con el uso del aciclovir o los corticoides, así Davis consiguió un $20 \%$ de respuestas mantenidas y DiBisceglie el $10 \%$.

Si utilizamos el "retrospectivoscopio", llama poderosamente la atención cuando, en uno de estos ensayos clínicos (3), se comenta los resultados del estudio piloto y se afirma: "En el estudio piloto, fueron tratados 10 pacientes con inter ferón durante 12 meses. En 8 las tranasaminasas bajaron hasta límites normales. Estos 8 han sido seguidos durante 2 a 4 años después de terminar el tratamiento con interferón, en 5 las transaminasas permanecen normales y en uno las transa. minasas están minimamente elevadas. En ese estudio se observó un $80 \%$ de respuesta inicial y un $60 \%$ de éxito a largo plazo...” “...Una posible explicación para esta diferencia (con sus cifras que son claramente más modestas) es la dosis más alta de interferón (2 a 4 MUI al día) suministradas durante un periodo más largo (un año) en el estudio piloto”. Pero esta observación no se tuvo en cuenta y finalmente se mantuvo, durante años, que el protocolo más eficaz era la administración de 3 MUI de interferón tres veces por semana durante 24 semanas primero y durante 48 hasta hoy. Todo ello, nos informa de que, durante mucho tiempo, nuestro conocimiento del por qué de los efectos terapéuticos del interferón eran escasos y los conocimientos sobre los mecanismos de persistencia y resistencia del virus de la hepatitis $\mathrm{C}$ a este tratamiento, nulos.

Por ello, aparecía como un elemento importante el análisis de los factores predictivos del resultado del tratamiento para tratar de determinar a priori que pacientes podrían beneficiarse de este tratamiento caro, con efectos colaterales importantes y con un porcentaje modesto de respuestas mantenidas.

A este respecto, en la Conferencia de Consenso de los NIH sobre el tratamiento de la hepatitis crónica $\mathrm{C}$, publicado en septiembre de 1997, Davis y Lau (4) analizan con brillantez y claridad el problema de los factores predictivos en cuanto a la sensibilidad, especificidad y valor predictivo positivo. Determinan que los factores que predecían una respuesta negativa al tratamiento eran una carga viral alta, el genotipo 1 y la presencia de cirrosis, pero su valor predictivo era solo ligeramente superior al $50 \%$ de los casos. Concluyendo que no es posible usar los factores predictivos para seleccionar a los pacientes que deben ser tratados.

En este contexto se enmarca el trabajo realizado por prestigiosos hepatólogos de la Sociedad Castellano-Leonesa para el Estudio de las Enfermedades Hepáticas (5). Estos autores analizan las lesiones anátomo-patológicas de la hepatitis $\mathrm{C} \mathrm{y}$ las correlacionan con la respuesta mantenida virológica al tratamiento con interferón alfa; realizan un estudio pormenorizado de cada biopsia hepática valorando, además del índice de Knodell, el grado de actividad y estadio de evolución y, sobre todo, las lesiones características de la hepatitis crónica por virus C. Llegan a una conclusión razonable e interesante: Ninguno de los factores histológicos y ninguno de los otros factores pre-tratamiento sirve para decidir con total precisión qué pacientes responderán al tratamiento con interferón.

Estos datos confirman lo que la observación clínica y la evidencia científica ponen de manifiesto, es decir, que en el momento actual la manera más exacta de predecir el resultado del tratamiento con interferón en monoterapia, en un caso concreto, es iniciar el tratamiento y observar el comporta- 
miento del ARN-VHC a los tres meses, si este sigue positivo las posibilidades de respuesta son escasas. Esta situación nos indica que nuestros conocimientos sobre la dinámica del virus C frente al interferón y la forma de actuación de este son muy limitados. Pero algo se ha avanzado, así los estudios de Zeuzem (6) y Neumann (7) nos informan de que la disminución de la viremia, bajo el efecto del interferón, se caracteriza por una primera caída rápida, que es dosis dependiente, más con 10 MUI que con 5 MUI, y que puede representar la disminución de la replicación viral en las células infectadas, seguida de una segunda fase de eliminación más lenta, que parece indicar la destrucción de los hepatocitos infectados. Estos estudios traen a primer plano el problema de la importancia de la dosis de interferón que estamos usando ya que probablemente es demasiado baja como ya indicaba el estudio piloto (1).

En el mismo sentido, investigaciones recientes insisten en el importante papel de las citoquinas en la hepatitis crónica $\mathrm{C}$. Los pacientes que se han recuperado espontáneamente de una infección por el virus $\mathrm{C}$ presentan un perfil de citoquinas que corresponde a una respuesta tipo Th1 de las células T cooperadoras, con la producción de IL-2 e IFN-gamma (8-11), lo mismo que pasa con los pacientes con hepatitis crónica que han aclarado el virus $C$ por efecto del interferón (12), mientras que los no-respondedores presentan una respuesta más vigorosa tipo Th2 con la producción de IL-4 e IL-10. A este res- pecto, conviene señalar que cuando se usa Ribavirina, conjuntamente con Interferón, se aumenta la producción de IL-2 e interferón-gamma y se suprime parcialmente las IL-4 e IL-10, alterándose el balance Th1/Th2 a favor de Th1. El estudio del perfil de las citoquinas en la hepatitis crónica $\mathrm{C}$ y el de las proteínas del virus $\mathrm{C}$ que son capaces de manipular el TNFalfa $(13,14)$ añadirá importantes datos a nuestro conocimiento de las virtudes del virus $\mathrm{C}$ para persistir y de las virtudes del tratamiento para desalojarlo.

El estudio de la dinámica viral durante el tratamiento, del papel de las citoquinas en la producción de la lesión hepática y de los mecanismos de persistencia y resistencia del virus $\mathrm{C}$ al tratamiento, nos permitirán un mejor conocimiento de los mecanismos íntimos de actuación del tratamiento antiviral y, quizás entonces, seamos capaces de determinar qué pacientes responderán y cuáles no. Hasta entonces nos tendremos que limitar a tratar a aquellos en que no este contraindicado el tratamiento combinado y que necesiten éste por el grado de lesión hepática con la esperanza de que este sea beneficioso al menos para disminuir el grado de inflamación.

\section{J. L. RODRÍGUEZ AGULLÓ}

Servicio de Aparato Digestivo. Hospital Universitario San Carlos. Madrid

\section{Bibliografía}

1. Hoofnagle JH, Mullen KD, Jones DB, Rustgi V, DiBisceglie A, Peters $\mathrm{M}$ et al. Treatment of chronic non-A, non-B hepatitis with recombinan human alpha interferon. A preliminary report. N Engl J Med 1986; 18; 315: $1575-8$.

2. Davis GL, Balark LA, Schiff ER, Lindsay K, Bodenheimer HC, Perrillo $\mathrm{RP}$ et al. Treatment of chronic hepatitis $\mathrm{C}$ with interferon alfa. A Multicenter Randomized, Controlled Trial. N Eng J Med 1989;321:1501-6.

3. Di Bisceglie AM, Martin P, Kassianides C, Lisker-Melman M. Murray $\mathrm{L}$, Waggoner J, et al. Recombinant interferon alfa therapy for chronic hepatitis C. A Randomized, Double Blind, Placebo-Controlled Trial. N Engl J Med 1989; 321: 1506-10.

4. Davis GL, Lau JYN. Factors predictive of a beneficial response to Therapy of hepatitis C. Hepatology 1997; 26(Suppl 1): 122S-127S.

5. Gento Peña E, López Morante A, Cordero Guevara J, Echevarría Iturbe C, Martín Lorente JL, Locos Goñi JL et al. Las lesiones anátomo-patológicas de la hepatitis crónica $\mathrm{C}$ como factores predictivos de respuesta mantenida al tratamiento con interferón. An Med Int 2001; 18: 351-356.

6. Zeuzem S. Clinical implications of hepatitis $\mathrm{C}$ viral kinetics. J Hepatol 1999; 31 (Suppl 1): 61-64.

7. Neumann AU, Lam NP, Dahari H, Gretch DR, Wiley TE, Layden TJ et

al. Hepatitis $\mathrm{C}$ viral dynamics in vivo and the antiviral efficacy al interferon alfa therapy. Science 1998; 282: 103-107.

8. Maher JJ. Cytokines: Overview. Semin Liv Dis 1999; 19: 109-115.

9. Koziel MJ. Cytokines in viral hepatitis. Seminar Liv Dis 1999;19:157-169.

10. Tsai SL. Liaw YF. Chen MH, et al. Detection of type 2-like T-helper cells in hepatitis $\mathrm{C}$ virus infection: Implications for hepatitis $\mathrm{C}$ virus chronicity. Hepatology 1997; 25: 449-458.

11. Woitos RP, Lechmann M, Jung G, et al. CD30 induction of cytokine profile in hepatitis $\mathrm{C}$ virus core-specific peripheral blood $\mathrm{T}$ lymphocytes. J Immunol 1997; 159: 1012-1018.

12. Cramp ME. Rossol S. Chokshi S et al. Hepatitis C virus-specific T-cell reactivity during interferon and ribavirin treatment on chronic hepatitis C. Gastroenterol 2000; 118: 346-355.

13. Kowdley KV. TNF-alpha in chronic hepatitis C: The smoking gun? Amer J Gastroenterol 1999; 94: 1132-1135.

14. Itoh Y, Okanoue T, Ohnishi N, Sakamoto M, Nishioji K, Nakagawa Y Minami M, Murakami Y, Kashima K. Serum levels of soluble tumor necrosis factor receptors and effects of interferon therapy in patients with chronic hepatitis C virus infection. Am J Gastroenterol 1999; 94 : $1332-40$. 